\title{
Cadeia produtiva da cachaça: um estudo de caso na agroindústria produtora de cachaça artesanal
}

\author{
Production chain of artisanal cachaça: the case of agroindustry producer of cachaça artisanal \\ Cadena productiva de la cachaça: el caso de la agroindutria productor de la cachaça artesanal
}

Recebido: 03/07/2021 | Revisado: 11/07/2021 | Aceito: 17/07/2021 | Publicado: 26/07/2021

\author{
Joyce Silva de Jesus \\ ORCID: https://orcid.org/0000 0002-7247-610X \\ Instituto Federal de Educação, Ciência e Tecnologia Goiano, Brasil \\ E-mail: joycekelly0911@gmail.com \\ Najla Kauara Alves do Vale \\ ORCID: https://orcid.org/0000-0002-3577-1513 \\ Instituto Federal de Educação, Ciência e Tecnologia Goiano, Brasil \\ E-mail: najla.vale@ifgoiano.edu.br
}

\begin{abstract}
Resumo
Este artigo tem como objetivo observar o processo produtivo da cachaça artesanal, a inserção da agroindústria no município de Palestina de Goiás-GO e sua aceitação mercadológica. A cadeia produtiva da cachaça é um setor econômico que integra diversas atividades em uma cadeia de produção, para fundamentar a análise, utilizou-se de pesquisas bibliográficas destinadas a levantar as informações sobre o sistema produtivo da cachaça, a metodologia, por conseguinte, caracteriza-se como exploratória e explicativa de natureza aplicada, com abordagem qualitativa, coletados através de questionários, entrevistas, visita in loco e aplicabilidade da ferramenta de gestão análise SWOT a fim de averiguar as potencialidades e gargalos dentro e fora da organização operacional. A análise dos resultados permite inferir que a empresa estudada fomenta a empregabilidade e renda no município, a empresa adota uma estratégia competitiva, privando pela qualidade da bebida e a comercialização direta ao consumidor.
\end{abstract}

Palavras-chave: Agronegócio; Matriz SWOT; Gestão estratégica; Mercado.

\begin{abstract}
This article aims to observe the production process of cachaça artisanal, the company's insertion in the municipality of Palestina de Goiás-GO and its market acceptance. The cachaça production chain is an economic sector that integrates several activities in a production chain. To support the analysis, bibliographic research was used to raise information about the cachaça production system, the methodology, therefore, characterized. as exploratory and explanatory of an applied nature, with a qualitative approach, collected through questionnaires, interviews, on-site visits and SWOT matrix find out potentially and bottleneck organization operational. The analysis of the results allows us to infer that the studied company promotes employability and income in the city, the company adopts a competitive strategy, depriving for the quality of the drink and direct marketing to the consumer.
\end{abstract}

Keywords: Agribusiness; SWOT Matrix; Strategic management; Marketplace.

\section{Resumen}

Este artículo tiene como objetivo observar el proceso de producción de Cachaça X, la inserción de la empresa en el municipio de Palestina de Goiás-GO y su aceptación en el mercado. La cadena productiva de la cachaza es un sector económico que integra actividades en una cadena productiva. Para sustentar el análisis, se utilizó la investigación bibliográfica para recabar información sobre el sistema de producción de la cachaza, la metodología, por lo tanto, caracterizada como exploratoria y explicativa de carácter aplicado, con un enfoque cualitativo, recogido a través de cuestionarios, entrevistas, visitas in situ y matriz DAFO. El análisis de los resultados permite inferir que la empresa estudiada promueve la empleabilidad y los ingresos en la ciudad, la empresa adopta una estrategia competitiva, privando por la calidad de la bebida y el marketing directo al consumidor.

Palabras clave: Agroindustria; Matriz DAFO; Gestión estratégica; Mercado.

\section{Introdução}

No Brasil, a cachaça surgiu no século XVI, período da colonização, tornando-se a primeira bebida destilada na América Latina, a princípio, não passava de uma garapa azeda consumida pelos escravos para suportarem a luta diária da 
escravidão. Posteriormente, com a inserção de novas tecnologias para o aperfeiçoamento da produção, a cachaça tornou-se um produto valorizado no mercado (Paiva et al., 2017).

A cadeia produtiva da cachaça passou por transformações de ordem institucional, mercadológica e política, desde a década de 1980 (Paiva, 2016). Sua popularização ocorreu devido a tentativa de registro da bebida pelos franceses, a partir desse processo os brasileiros perceberam o potencial desse produto. Por muito tempo, a cachaça foi considerada um produto de fácil aquisição pelo baixo valor, a partir do século XX ganhou notoriedade com produtos exclusivos e mais elaborados (Paiva et al., 2017).

Segundo a Agência Embrapa de Informação Tecnológica-AGEITEC (2019), a cachaça é produzida em todos os Estados brasileiros, mesmo naqueles que o cultivo da cana-de-açúcar não é favorável, dados dos anos 2006 e 2019, demostram que a maior produção de cachaça no Brasil concentra nos estados de São Paulo, que responde por cerca de $45 \%$ da oferta total, Pernambuco (12\%), Ceará (11\%), Goiás/Minas Gerais/Rio de Janeiro ( $8 \%$ cada), Paraná (4\%), Bahia (2\%) e Paraíba (2\%).Em 2018, a cachaça foi exportada para 77 países, com mais de 50 empresas exportadoras, gerando uma receita de US\$15,61 milhões, com a produção de 8,41 milhões de litros de cachaça. Os principais destinos da cachaça foram: Estados Unidos, Alemanha, Paraguai, Portugal e Itália (Instituto Brasileiro da Cachaça-IBRAC, 2018).

A produção de cachaça artesanal tem potencial econômico, porém enfrenta um alto índice de informalidade (PAIVA et al., 2017). Portanto, é de suma importância que as empresas desse segmento sejam valorizadas e estudadas para que sejam veículo de fomento e informação para aqueles que, ainda, desenvolvem essa atividade na informalidade. Nesse sentido, o trabalho tem como objetivo geral fazer um estudo de caso na agroindústria produtora de cachaça artesanal, localizada no município de Palestina de Goiás-GO, tendo como suporte a ferramenta de gestão estratégica matriz SWOT com o intuito de averiguar as potencialidades e os gargalos dentro e fora do ambiente operacional da agroindústria, bem como identificar o nível de inserção da empresa no mercado, de tal modo, esse estudo é relevante, pois resultará inúmeras informações, as quais serão essenciais para alavancar a comercialização e a produção servirá de aporte a eventuais trabalhos futuros.

\section{Metodologia}

A abordagem metodológica adotada foi qualitativa, pois a coleta de dados no ambiente natural, propícia a compreensão da realidade em profundidade, realiza descrições, interpretações e atribuição de significados, investigação de concepções, opiniões e práticas. De acordo com Appolinário (2006) a pesquisa qualitativa possibilita analisar dados adquiridos e posteriormente estabelecer informações vastas em relação a realidade futura.

No primeiro momento, foi realizada uma pesquisa bibliográfica que permitiu identificar o problema da pesquisa, bem como identificar as técnicas e ferramentas que permitiram a criação do trabalho prático. Para desenvolvimento da pesquisa bibliográfica, foram utilizados livros, documentações, manuais técnicos, ferramentas, monografias, dissertações, teses, artigos e sites. A pesquisa bibliográfica possibilita reunir informações científicas voltadas as teorias a fim de explicar um problema a partir de referências publicadas em artigos, livros, teses e dissertação (Cervo, 2007). Subsequentemente, foi executado um estudo de caso, com o intuito de visar maneiras na expansão de conhecimentos e um diagnóstico envolvendo a configuração comercial e produtiva, através de entrevistas, aplicação de questionário apenas com o proprietário a título de averiguar o processo de produção e comercialização, visita in loco com o proprietário da empresa e posteriormente realizou-se análise por meio da matriz SWOT, a fim de averiguar as potencialidades e ameaças do ambiente interno e externo da agroindústria.

Segundo Pontes (2019) a matriz SWOT é uma ferramenta que possibilita analisar o ambiente interno e externo da organização, divididos em quadrantes, onde a análise dos pontos fracos e fortes, oportunidade e ameaça servem para averiguar a desenvoltura da organização e criar estratégias para aprimorar o setor. Em relação ao estudo de caso, segundo Pinheiro 
(2010) é um método profundo e exaustivo que possibilita recolher informações e adquirir conhecimento detalhados sobre algum assunto.

Posteriormente, foram acompanhadas as operações do ambiente de produção com o intuito de identificar as características produtivas e as etapas de execução do trabalho a fim de compreender e realizar o mapeamento dos processos, bem como, entrevistas diretas com os atores dos processos observados. De acordo com Ruiz (2013) essa abordagem feita diretamente com as pessoas em busca de possíveis informações é aclamada diálogo, o qual tem como objetivo colher informações relevantes de determinada fonte para agregar na desenvoltura da pesquisa em andamento.

Segundo pinheiro (2010) no que se refere ao questionário é uma ferramenta designada a colher informações de maneira simples, ele possui uma linguagem de fácil entendimento e uma série de perguntas abertas, fechadas ou múltipla escolha onde o informante deve responder conforme seu conhecimento perante o assunto exposto.

A pesquisa foi de natureza aplicada, pois procura produzir conhecimentos práticos dirigidos à solução de problemas específicos. O objetivo do estudo foi explicativo, pois procura identificar os fatores que causam um determinado fenômeno, aprofundando o conhecimento da realidade. Assim o método de pesquisa adotado na agroindústria produtora de cachaça artesanal, localizada no município de Palestina de Goiás, foi de suma importância para o desenvolvimento de um cenário geral perante a empresa estudada.

\section{Resultados e Discussão}

A Agroindústria produtora de cachaça artesanal, situa-se na zona rural, Rodovia Go $221 \mathrm{Km} 67$ esq. 6 Km, Município de Palestina de Goiás, no sudoeste Goiano, fazendo limites ao norte com Arenópolis, a leste Amorinópolis, e ao sul com Caiapônia, ambos os municípios estão situados no Estado de Goiás, a 280 km da capital Goiânia. A empresa está constituída num terreno da própria família, cuja área de instalação da indústria é de $2.500 \mathrm{~m}^{2}$.

A inserção da empresa no município de Palestina de Goiás fomenta a empregabilidade e concomitantemente alavanca a economia. Nessa perspectiva, a empresa estudada segue as etapas conceituais existentes no ramo da cadeia do agronegócio brasileiro relacionado a integração de atividades produtivas. Dividida em três etapas: antes, dentro e depois da porteira. O termo antes da porteira faz referência aos itens necessários para o setor agrícola, ou seja, os insumos (fertilizantes, máquinas, implementos e equipamentos agrícolas). No que se refere ao seguimento dentro da porteira se enquadra o plantio, o manejo, colheita, armazenagem, embalagens entre outros. Já no processo fora da porteira remete a questão da armazenagem de produtos processados, comercialização e logística.

Conforme a Figura 1 a matéria prima destinada a produção da cachaça é oriunda da própria fazenda, o canavial tem área total de 25 hectares (5,165 alqueires goiano), nessa processo não ocorre a aplicação de agrotóxicos, visto que a inserção de fertilizantes químicos pode afetar as características sensoriais da bebida, sendo assim a empresa estudada faz uso de adubos orgânicos provenientes da própria palha da cana, colhida, deixada sobre o solo. 
Research, Society and Development, v. 10, n. 9, e28210917839, 2021

(CC BY 4.0) | ISSN 2525-3409 | DOI: http://dx.doi.org/10.33448/rsd-v10i9.17839

Figura 1: Fluxograma de produção da cachaça artesanal.

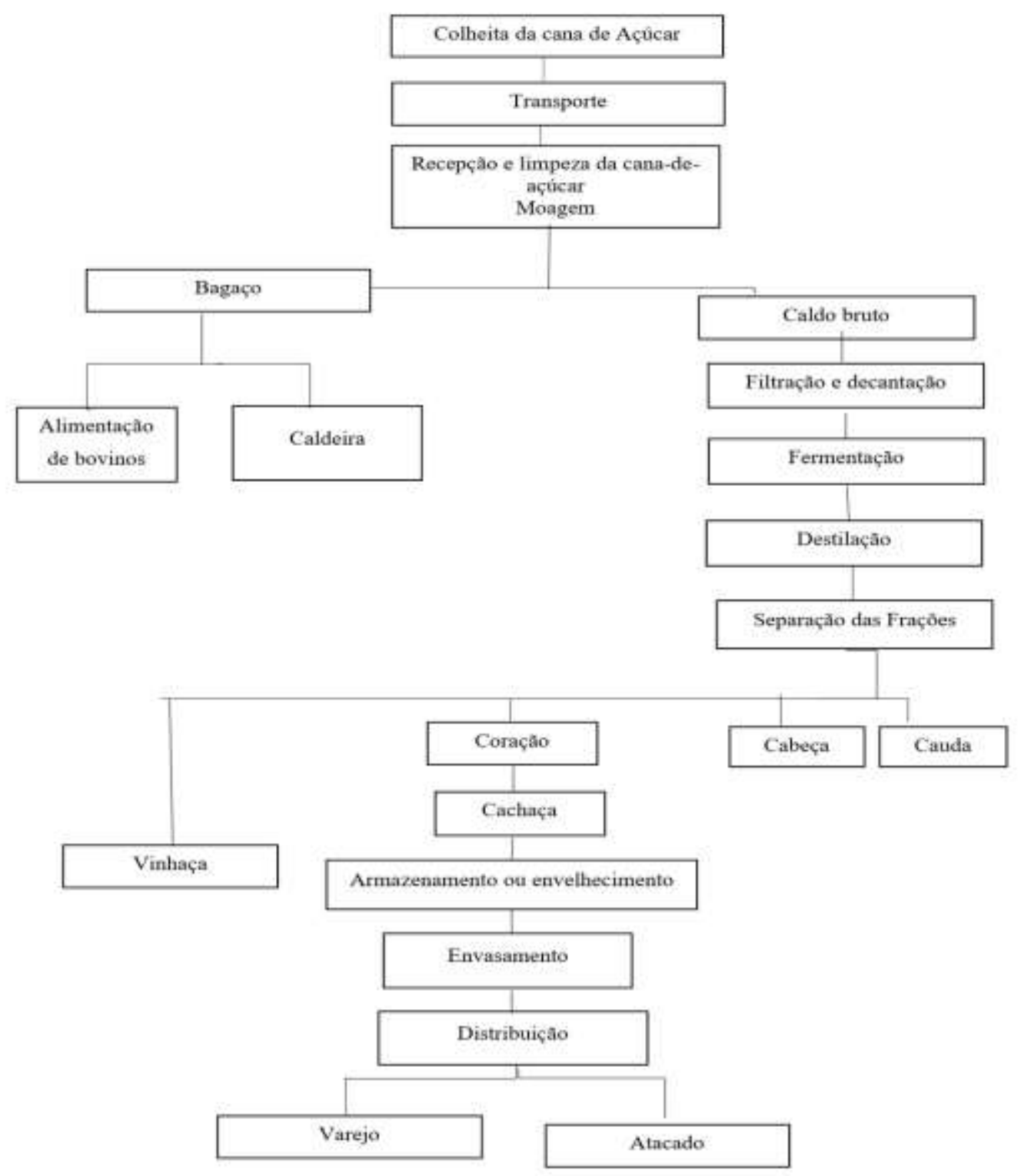

Fonte: Autoras (2019).

A colheita é realizada manualmente, pois a empresa não possui um maquinário específico para efetuar essa operação, o carregamento da matéria prima é efetuado em carrocerias de madeira acopladas a um trator.

A Figura 2 abaixo ilustra a matéria-prima após a colheita, apta a ser destinada a moenga. 
Figura 2: Cana-de-açúcar após o corte.

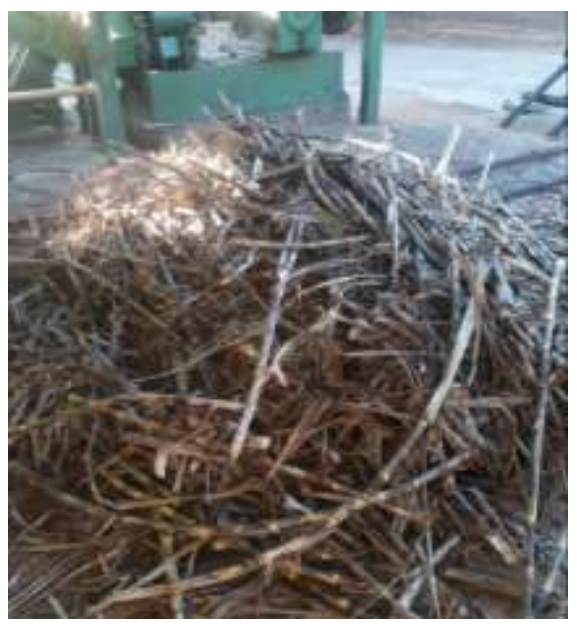

Fonte: Arquivo da pesquisa (2019).

Após o corte, as canas são destinadas as moengas (engenho) em seguida, o líquido obtido é purificado em dois ou mais cantadores. O caldo da cana quando sai do processo de extração contém uma quantidade de impurezas, a remoção desses fragmentos sólidos insolúveis (bagacilhos, areia etc.) é efetuada por uma peneira, feito isso, verifica o $\mathrm{pH}$ (teor de acidez) e o Brix ${ }^{1}$ (teor de açúcares).

A Figura 3 explana o caldo da cana-de-açúcar caindo sobre a peneira, com a finalidade de remover os sólidos insolúveis

Figura 3: Peneira de remoção dos sólidos insolúveis.

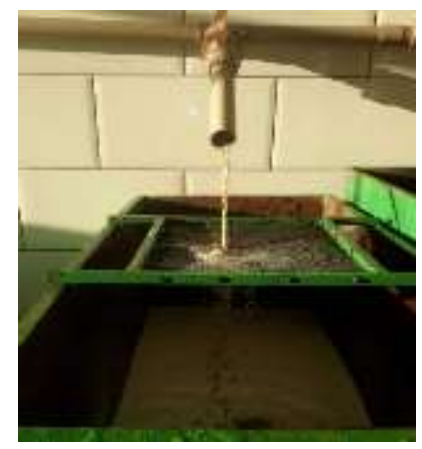

Fonte: Arquivo da pesquisa (2019).

Posteriormente, a temperatura do caldo é ajustada com a dorna, onde já se encontra o pé-de-cuba, também conhecido como isca ou fermento. O caldo é transferido para a dorna e assim inicia o processo de fermentação. O fermento (leveduras) utilizado é natural, produzido através da adição de quirera de milho, e farelo de arroz e/ou de soja. A Figura 4 abaixo, ilustra a dorna de decantação.

\footnotetext{
${ }^{1}$ Brix é a porcentagem em massa de sólidos solúveis contidos em uma solução de sacarose quimicamente pura, ou seja, o brix mede a pureza do caldo extraído da moagem da cana-de-açúcar (Schoeninger et al., 2014).
} 
Figura 4: Dorna de decantação.

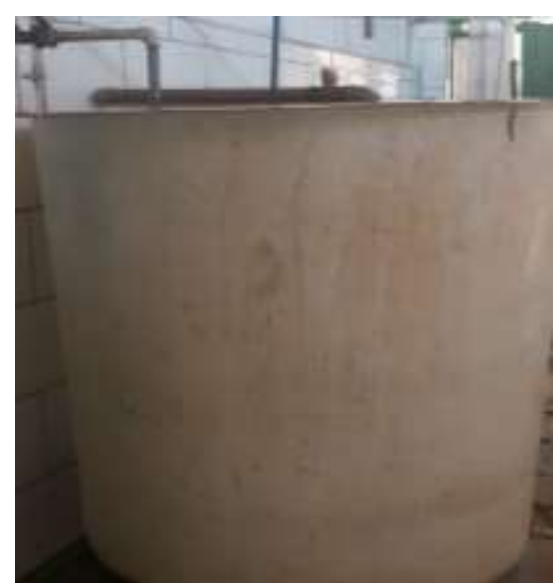

Fonte: Arquivo da pesquisa (2019).

A duração ideal do processo de fermentação situa-se entre 20 e 36 horas. Se este tempo for prolongado, o produto apresentará acidez elevada, o que provocará a sensação de "queima" durante sua ingestão. A empresa possui uma sala com 16 (dezesseis) dornas de fermentação.

Finda a etapa da fermentação, inicia-se a fase de alambique, a primeira parcela da destilação, chamada "cabeça" (contendo substâncias nocivas, tais como aldeídos, e metanol, entre outras), e a última parcela, chamada "cauda" (contendo álcool amílico, que provoca dor de cabeça, ressaca, gosto e cheiro ruins na boca), representando de $7.5 \%$ a $22.5 \%$, do volume total, respectivamente, são descartadas. Somente a parcela central da destilação, conhecida como "coração" responsável por $70 \%$ do volume total, é destinada à fase de envelhecimento. A Figura 5 explana um dos alambiques de aço utilizados na agroindústria.

Figura 5: Alambique de aço.

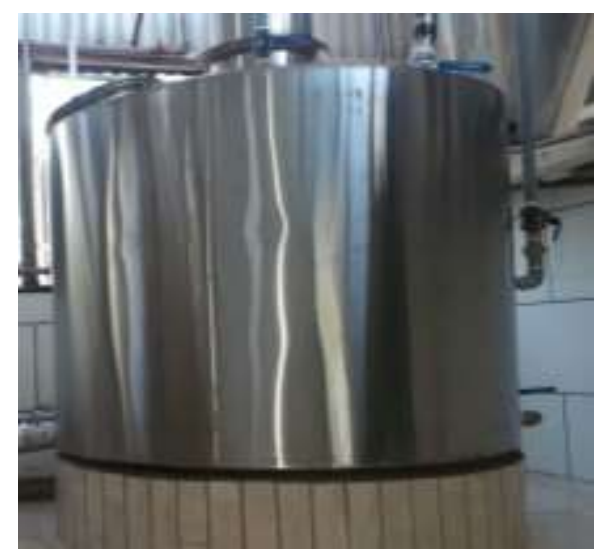

Fonte: Arquivo da pesquisa (2019).

A agroindústria estudada realiza o envelhecimento e armazenamento da cachaça em barris de madeira, tais como o jequitibá e o carvalho, a fim de agregar valor no produto, consequentemente atribuindo características únicas a bebida visando eliminar a acidez e possíveis substâncias indesejáveis.

A Figura 6, ilustra um dos barris de madeira existente na agroindústria e sua capacidade de armazenamento de cachaça. 
Figura 6: Barril de madeira jequitibá, com capacidade de 400 litros de cachaça.

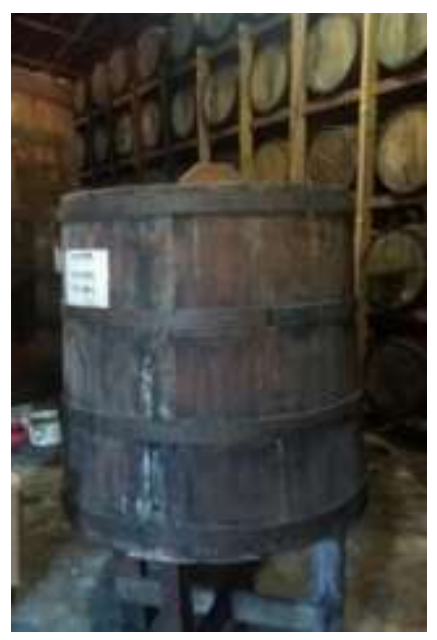

Fonte: Arquivo da pesquisa (2019).

\subsection{Envasamento da cachaça}

O tempo de envelhecimento da cachaça fica a critério do produtor, feito isso, a bebida está pronta para ser envasada (SEBRAE,2012). Normalmente método de envasamento da cachaça é realizado de maneira manual, tendo-se as garrafas de plástico de $485 \mathrm{ml}$ de 1,2 e 5 Litros, e as garrafas cilíndrica de vidro de $700 \mathrm{ml}$.

Após o envasamento é realizado uma pesagem, essa pesagem consiste em seguir os requisitos sanitários da vigilância, sendo de $958 \mathrm{~g}$ ou $1 \mathrm{~kg}$. A empresa em si coloca $958 \mathrm{~g}$ devido oscilações de balança e evaporação.

A Figura 7 ilustra a engarrafadora de enchimento semiautomático, fabricado com aço inoxidável, capacidade de 6 bicos, capazes de realizar o engarrafamento de 6 garrafas ao mesmo tempo.

Figura 7: Engarrafadora de enchimento semiautomático.

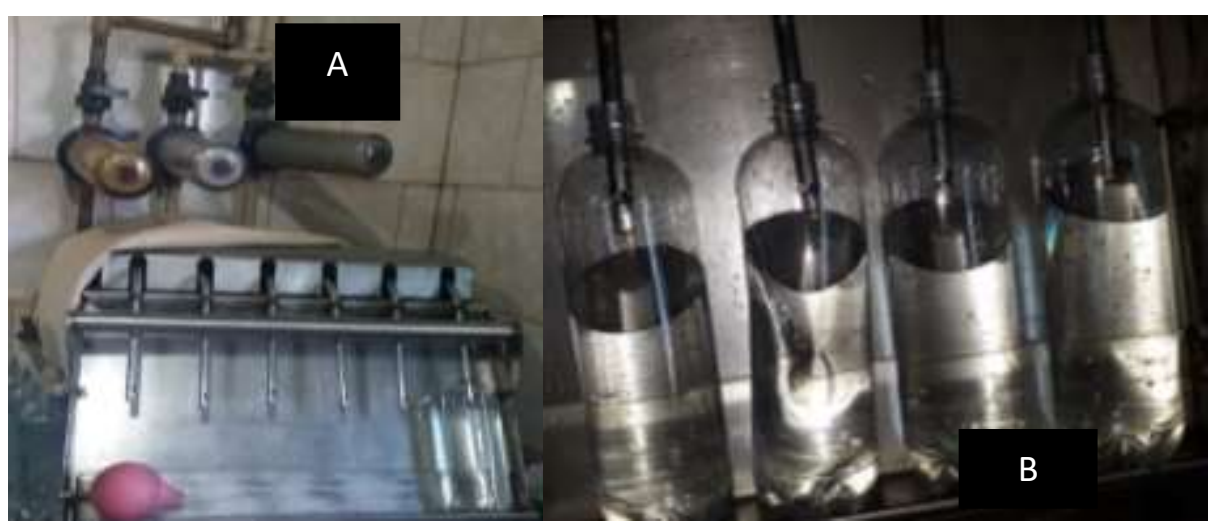

Fonte: Arquivo da pesquisa (2019).

A Figura 8 abaixo explana uma garrafa pet 1 litro, sendo pesada conforme as normas da vigilância sanitária. 
Figura 8: Balança digital de pesar garrafa de cachaça.

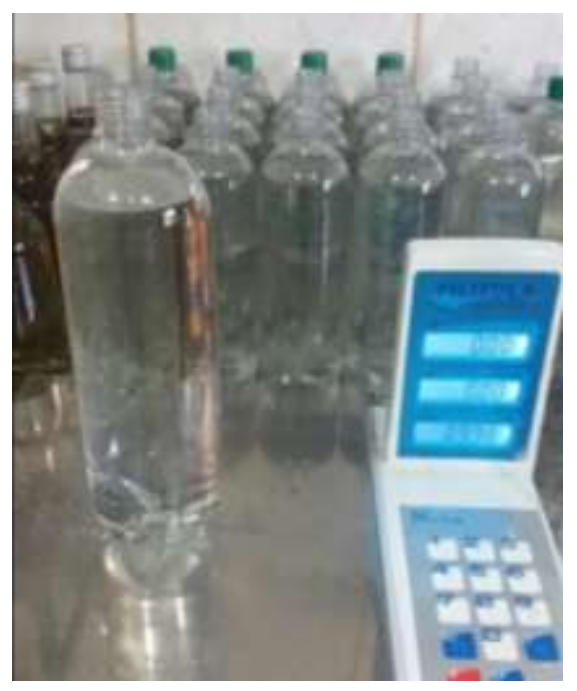

Fonte: Arquivo da pesquisa (2019).

As garrafas cheias são fechadas com tampas de plástico ou metal, as tampas de metal são destinadas as garrafas de vidro. As garrafas tampadas passam por uma análise a fim de averiguar e eliminar a hipótese da existência de algum cisco que possa comprometer a qualidade do produto, feito isso, a garrafa é destinada ao processo de rotulagem manual. Por último, são embaladas em fardos de plástico com capacidade de 12 unidades ou em caixas de papelão com capacidade de 3 a 4 unidades, como é o caso do Kit da reserva especial, posteriormente, estão aptas a irem para o mercado consumidor.

\subsection{Distribuição}

A distribuição da cachaça é realizada através das redes atacadista e varejista, com intuito de atender além do mercado local e regional de Goiás, como também de outros estados da união, fomentando a rentabilidade econômica do município de Palestina de Goiás. A Figura 9 apresenta esquematicamente o processo de distribuição da agroindústria produtora de cachaça artesanal:

Figura 9: Representação esquemática do processo de distribuição da agroindústria.

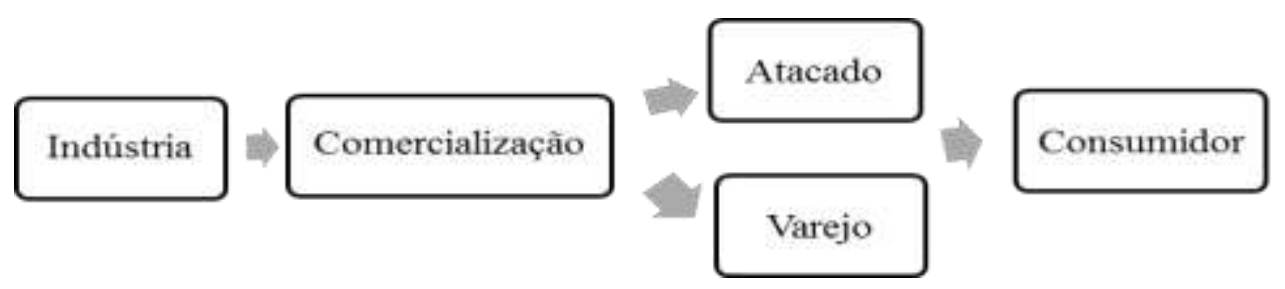

Fonte: Arquivo da pesquisa (2019).

A comercialização dos produtos acabados é realizada no método atacadista e varejista, usufruindo as ferramentas dos canais de comercialização, tais como: site, telefone e vendedor. Com o intuito de atender e satisfazer os diversos consumidores existentes fora do mercado local e regional de Goiás, como demais Estados da União, São Paulo, Mato Grosso, Mato Grosso do Sul, Minas Gerais, Santa Catarina, Paraná e Brasília, consequentemente, fomentando a rentabilidade econômica do município de Palestina de Goiás. 
A distribuição e comercialização dos produtos acabados, é efetuada por um vendedor com o auxílio de um automóvel Fiorino Fiat, essa logística é realizada nos municípios circunvizinho da cidade de Palestina de Goiás, nos demais estados a distribuição é feita com o auxílio dos correios e transportadoras.

Em relação ao controle de caixa, estoque, despesas, vendas, entradas e saídas de mercadorias, cadastro de produtos e clientes é gerenciado por um software, idealizado e desenvolvido pelo gestor da empresa, o software proporciona exercer as atividades diária da empresa. O programa proporciona acessar informações dos dois escritórios situados nas cidades de Palestina de Goiás e Goiânia sem a necessário de deslocar do escritório na fazenda.

Referenda a gestão de desempenho empresarial o tópico vindouro apresenta uma análise SWOT da empresa estudada, com o intuito de entender o ambiente em que está inserida e adquirir informações relevantes para planejar o futuro.

\section{Matriz SWOT da Agroindústria produtora de cachaça artesanal}

Ao utilizar a ferramenta de SWOT, temos a análise de dois pontos: Ambiente interno e ambiente externo, os quais ampliam a visão do contexto estratégico da organização estudada.

O quadrante (Figura 10) abaixo demostra a Matriz SWOT da agroindústria o qual nos possibilita visualizar os fatores interno e externo da organização. A empresa possui características que potencializam suas vantagens competitivas com a abertura de novos mercados e a baixa concorrência, entretanto, possui aspectos que merecem ser averiguados para evitar percas inestimável. As ameaças inerentes à atividade consistem na alta carga tributária, altos custos dos combustíveis e o clima, pois a fazenda produz a matéria-prima.

Figura 10: Matriz SWOT.

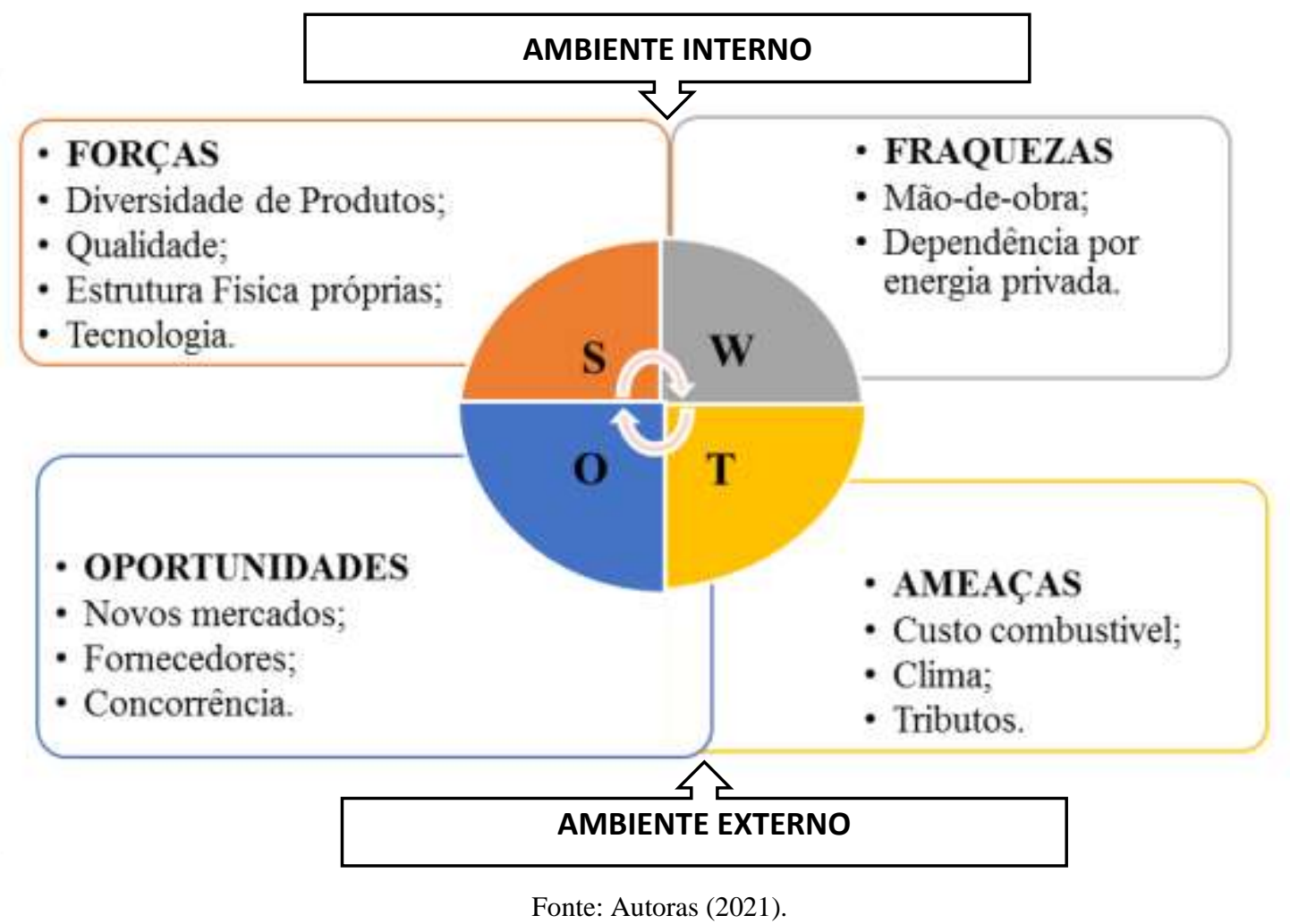

\section{Considerações Finais}

A inserção da agroindústria no município de Palestina de Goiás fomenta a empregabilidade e concomitantemente alavanca a economia. Nessa perspectiva, a empresa estudada segue as etapas conceituais existentes no ramo da cadeia do 
agronegócio brasileiro relacionado a integração de atividades produtivas. A empresa por ser de pequeno porte e por apresentar uma produção, predominantemente, artesanal possui uma aceitabilidade satisfatória no que se refere a sua inserção no mercado, isso se dá pela qualidade do produto e a desenvoltura no processo de comercialização, visto que, a empresa utiliza a tecnologia como sua aliada, a qual possibilita manter o contato com diversos compradores nos seguintes Estados: Goiás, São Paulo, Mato Grosso, Mato Grosso do Sul, Minas Gerais, Santa Catarina, Paraná e Brasília, ou seja, são vantagens que possibilitam sua expansão mercadológica. Referenda a gestão de desempenho empresarial com embasamento na matriz SWOT, observa-se que as informações adquiridas com o resultado do diagnóstico identificou os aspectos presentes no processo interno e externo da organização, aspectos gradativamente relevantes para potencializar a comercialização e o sistema de produção, entretanto, possui aspectos negativos que merecem ser averiguados, como a questão do alto custo do combustível onde a empresa pode aderir a estratégia de, futuramente, produzir o próprio combustível, apresenta inúmeras oportunidades como o acesso a novos mercados, possiblidade de expansão da produção e a inovação do seu produto.

\section{Referências}

Ageitec. Cana-de-açúcar. https://www.agencia.cnptia.embrapa.br/gestor/cana-de-acucar/arvore /CONT000fiog1ob502wyiv80z4s473agi63ul.html

Appolinário, F. (2011). Metodologia da ciência: filosofia e prática da pesquisa. Cegage Learning

Bertoncello, A. G., Silva, K. F. R., \& Godinho, Â. M. M. (2016). Indicação Geográfica Protegida: Agrega Valor ao Produto e Induz ao Desenvolvimento Regional? O Caso da Cachaça de Paraty. Desafio Online, 4(1), 1-27.

Cervo, A. L., \& Bervian, P. A. (2007). Metodologia científica. Pearson Prentice Hall.

Cunha, A. D. S. (2018). Análise do mercado de cachaça artesanal no Rio Grande do Sul.

De Araújo Silva, G. B., \& Lima, J. R. O. (2019). Industrialização, competitividade e agroindústria: uma breve análise do complexo agroindustrial do Recôncavo Sul da Bahia. Bahia Análise \& Dados, 29(1), 217-228.

De Castro, A. M. G., Lima, S. M. V., \& Cristo, C. M. P. N. (2002). Cadeia produtiva: marco conceitual para apoiar a prospecção tecnológica. XXII Simpósio de Gestão e Inovação Tecnológica. Salvador.

De Oliveira, A. M. L. (2011). O processo de Produção da Cachaça Artesanal e sua Importância Comercial.

Fajardo, S. (2008). Complexo agroindustrial, modernização da agricultura e participação das cooperativas agropecuárias no estado do Paraná. Caminhos de Geografia, 9(27).

Gassen, G. S., de Peder, L. D., \& da Silva, C. M. (2017). Análise da qualidade microbiológica do caldo de cana comercializado em um município da região oeste do paraná. In Colloquium Vitae. 9, 07-12.

Gonzales, T. S. (2017). Projeto de climatização de alto desempenho para adega de cachaça.

Ibrac. Instituto Brasileiro de Cachaça. Mercado externo. http://www.ibrac.net/index.php?option=com_content\&view=article\&id=47\&Itemid=44

Mattos, D. S. (2017). Sistemas de manejo e variedades de cana-de-açúcar na composição da vinhaça de cachaça de alambique.

Martins, M. F. (2018). Gestão e tecnologia em engenhos produtores de cachaça no brejo da paraíba-brasil.

Oliveira, F. M. D. (2017). Arranjo produtivo de cachaça da região Salinas-MG: aprendizagem, tecnologia e viabilidade econômica.

Paiva, A. L. D., Souza, R. B. D., Barreto, I. D. D. C., \& Brito, M. J. D. (2017). Fluxo das Exportações Brasileiras de Cachaça: traços da influência do Estado no setor. Revista de Economia e Sociologia Rural, 55(4), 733-750.

Palencia, N. P. (2016). Complexo Agroindustrial do Leite no Brasil: Indicadores Socioeconômicos, Adoção de Tecnologias e Transformações nas Últimas Décadas. Revista de Economia do Centro-Oeste, 2(2), 55-72.

Pinheiro, J. M. D. S. (2010). Da iniciação científica ao TCC: uma abordagem para os cursos de tecnologia. Ciência Moderna.

Pontes, K. D. S. (2019). Análise SWOT: uma contribuição para a gestão de uma microempresa familiar revendedora do ramo alimentício do agreste paraibano. Roos, A. (2012). Agricultura: dos povos nômades aos complexos agroindustriais. Revista Eletrônica em Gestão, Educação e Tecnologia Ambiental, 7(7), 1423-1429.

Ruiz, João Álvaro. (2013). Metodologia Científica: guia para eficiência nos estudos. Atlas

Samel, A. N., Batista, A. P., \& da Silva César. (2015). A evolução tecnológica versus produção artesanal: o caso da cachaça de Paraty-RJ. 
Research, Society and Development, v. 10, n. 9, e28210917839, 2021

(CC BY 4.0) | ISSN 2525-3409 | DOI: http://dx.doi.org/10.33448/rsd-v10i9.17839

Sebrae (2012). Cachaça artesanal - série estudos mercadológicos. http://www.bibliotecas.sebrae.com.br/chronus/arquivos_chronus/bds/bds.nsf/444c268 3e8debad2d7f38f49e848f449/\$file/4248.pdf

Sebrae- Serviço Brasileiro de Apoio às Micro e Pequenas Empresas. Ferramenta: analise swot estratégias.https://www.sebrae.com.br/Sebrae /Portal\%20Sebrae/Anexos/ME_Analise-Swot.PDF

Sebrae. Análise SWOT: como aplicar no planejamento da sua empresa. http://ww.sebrae.com.br/sites/PortalSebrae/ufs/pr/artigos/analise-swot-como-aplicarno-planejamento-da-sua-empresa.

Silva, D. T., de Rezende, A. A., \& da Silva, M. D. S. (2018). A Coopama e a Cadeia de Produção da Cachaça Baiana "Abaíra". Revista de Extensão e Estudos Rurais, 7(2), 241-265.

Silva, L. D. (2005). Cadeia produtiva de produtos agrícolas. Boletim técnico, 1, 1-10.

Silva, T. R., Medeiros, M. V. B., \& Medeiros, G. R. N. (2018). Gestão de Riscos no framework SCRUM utilizando Análise Swot. Revista de Tecnologia da Informação e Comunicação da Faculdade Estácio do Pará, 1(1), 48-57.

Souza, S. O. (2001). Desenho e análise da cadeia produtiva dos vinhos finos da Serra Gaúcha. Porto Alegre: Dissertação (Mestrado em Engenharia da Produção). Programa de Pós-Graduação em Engenharia da Produção/Universidade Federal do Rio Grande do Sul.

Schoeninger, V., Coelho, S. R. M., \& Silochi, R. M. H. (2014). Cadeia produtiva da cachaça. Energia na Agricultura, 29(4), 292-300. 